\title{
Development of Wind Tunnel for Ultrafine Palm Oil Fuel Ash Separator
}

\author{
Sylvester Kenneth Sedah ${ }^{1}$, Ana Sakura Zainal Abidin ${ }^{1, a}$, A. Rigit ${ }^{1}$, Mohd Azlan Ismail ${ }^{2}$, Raudhah Ahmadi ${ }^{3}$, and Md Abdul \\ Mannan ${ }^{3}$ \\ ${ }^{1}$ Department of Mechanical and Manufacturing Engineering, Faculty of Engineering, Universiti Malaysia Sarawak, Kota Samarahan, \\ Sarawak, Malaysia \\ ${ }_{2}^{2}$ Faculty of Engineering, Universiti Malaysia Sabah, Kota Kinabalu, Sabah, Malaysia \\ ${ }^{3}$ Department of Civil Engineering, Faculty of Engineering, Universiti Malaysia Sarawak, Kota Samarahan, Sarawak, Malaysia
}

\begin{abstract}
Palm Oil Fuel Ash (POFA) is a pozzolanic material that has great potential in concrete production. POFA sizes range from 1 to $10 \mu \mathrm{m}$ is preferable. Thus, there is a need for efficient method to separate the POFA according to the sizes needed. This study explores the idea of using a simple wind tunnel as a separator for ultrafine POFA. The existing operation of the wind tunnel is simulated using ANSYS-CFX, a numerical modelling software. The identified weakness of the wind tunnel design is located at the hopper. The wind tunnel is simulated with a different air inlet velocity in order to visualize the air flow profile as well as air flow energy at the hopper. Different air inlet velocities has a similar air flow profile but the air flow intensity is different. For further study the modifications of the air flow profile were conducted. By altering the hopper angle shows that the air flow profile is changed. Based on the simulation results, the hopper at $60^{\circ}$ yields the best flow characteristic. At angle $60^{\circ}$ of the hopper, the air flow is mostly directed downward into the tunnel and the air flow energy is low. Therefore, it allows the POFA to be directed into the tunnel and reduced the ultrafine POFA losses at the tip of the hopper. This practical method utilizes a simple open wind tunnel that enables the process to be more efficient and cost efficient thus the production of ultrafine POFA can be increased.
\end{abstract}

\section{Introduction}

Palm oil has become a significant product in the global market. Palm oil is obtained from a plant that is oil palm tree, scientifically known as Elaeis guineensis [1]. In tropical countries, palm oil is an important commodity. Malaysia is one of the producer and exporter in the world [2]. Malaysia has endeavoured to advance with the increasing demand for vegetable oil as palm oil industry is one of the biggest agricultural industries.[3].

As millions of tons of the by-product known as Palm oil fuel ash (POFA) have been disposed off annually; it indirectly contributed a negative impact to the environment. Researches had conducted many studies to convert this waste material into useful products. POFA has been identified as pozzolanic material [4] which is suitable to be used in concrete production in 20th century [5]. This waste material can be integrated as a partial cement replacement to produce various types of concrete which consume lesser amount of cement, more environmental friendly and economical [4]. As the fineness of the POFA influenced the strength of the concrete [3], it is essential to have a proper method to separate the ultrafine POFA in order to get ultrafine POFA sizes range from 1 to $10 \mu \mathrm{m}$. [6].

Therefore, an application of wind tunnel concept in separating the ultrafine POFA had been applied.
Fundamentally, at suitable velocity of air, the fine and light particles will be blown away and the heavy particle will drop. The wind tunnel; a tube-like-tunnel at varying cross sections is made to blow through them at certain speed [7]. It was classified as open wind tunnel with blowdown principle in which a fan was located at the inlet of the tunnel. The wind tunnel has five main components which are a settling chamber, contraction cone, test section, diffuser, and drive section [8].

The proposed wind tunnel for this analysis as compared to the existing wind tunnel by other researches is simpler in design with lower cost and safer to build [9]. The wind tunnel sensitive parameters that are commonly observed in these area of studies are pressures, forces, and direction of air flow impacting the tested models, such as spacecraft, cars, trucks, trains, or entire cities [7]. The behaviour of a model can be predicted visually.

In this study, further research on the design of the wind tunnel is carried out to extend the practical method of separating the ultrafine POFA. Previously, it was proven that ultrafine POFA was able to be collected at a certain distance in the tunnel [6]. Figure 1 shows the design of the wind tunnel with a length of 10 metres and it consists of three main components; diffuser, hopper and tunnel.

Application in using numerical modelling software, enables better understanding of the flow pattern, reducing

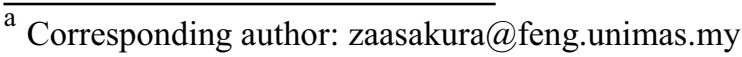


number of repetitive experiments that consequently cut down on experimental cost [10].

The research utilized POFA collected from Bau Palm Oil Mill (BAPOM) which is located in Bau, Sarawak. The study focused on improving the wind tunnel design that must be simple and lower construction cost, consequently allowing for low cost research applications in other faculty researches regarding ultrafine POFA. The wind tunnel is designed to cater for the separation of ultrafine POFA obtained from BAPOM only.

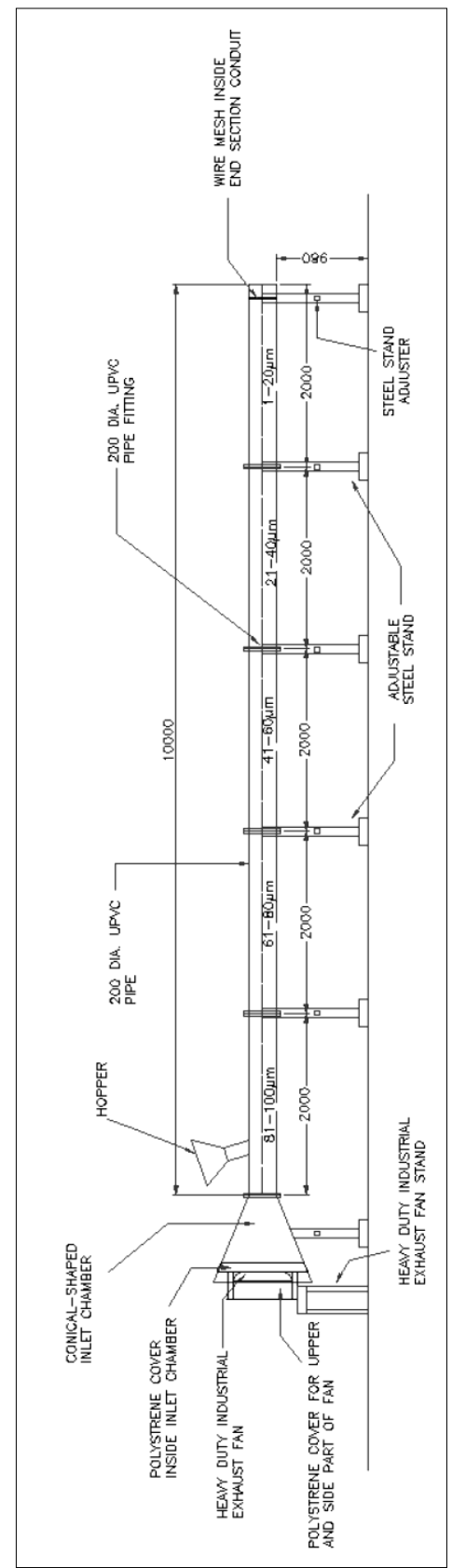

Figure 1. Schematic diagram of the wind tunnel

\section{Methodology}

In this study, the CFD model was used to simulate the air flow across the wind tunnel with a hopper positioned between the flow passages. The air flow can be simulated in the wind tunnel especially when the air passed through the hopper section. The simulation flow domains take into account the overall internal flow region of the wind tunnel, however, the observed region was the air passing through the hopper channel.

The meshing is set with element size of 0.01 metres, with high smoothing and fast transition setting as shown in Figure 2.

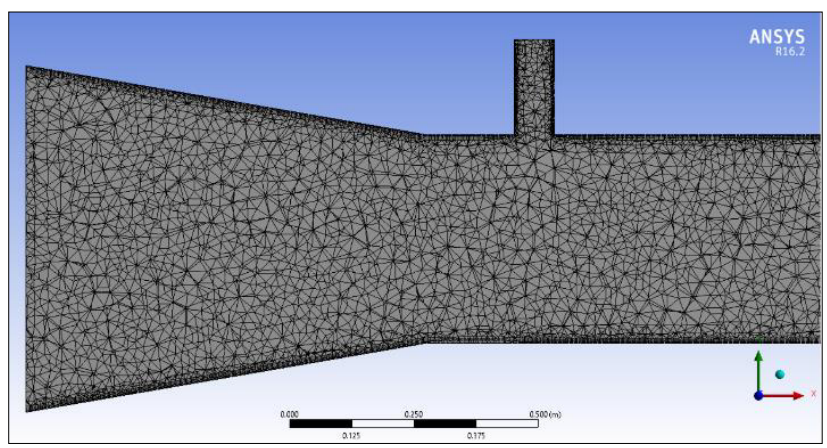

Figure 2. Wind tunnel with fine mesh

The inflation meshing setting was focused on the hopper in order to see the air flow changes when passing through the hopper as shown in Figure 3.

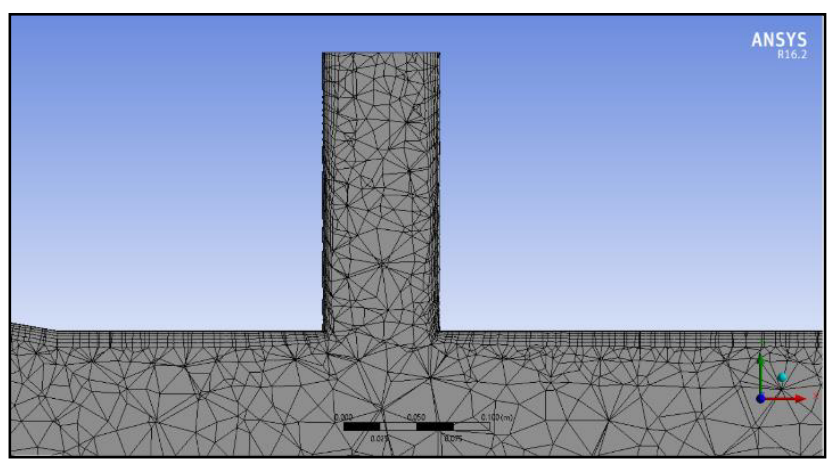

Figure 3. Inflation on the hopper

The simulation of air flow inside the wind tunnel was set on the basis of the following basic assumptions:

- Steady state condition

- Constant fluid properties

- Incompressible fluid flow

- Smooth wall surface

The boundary conditions were set as shown in Table 1. These conditions specified the flow on the boundaries of a physical model. The boundary condition would determines the behaviour of the solution given a set of differential equations at the boundary of its domain.

Table 1. Domain and boundary type

\begin{tabular}{|c|c|}
\hline Domain & Boundary Type \\
\hline Air inlet & Inlet \\
\hline Hopper opening & Opening \\
\hline Outlet & Opening \\
\hline Wind tunnel body & Wall \\
\hline
\end{tabular}


Advection scheme in high resolution technique was used to simulate the air flow profile in the wind tunnel. Turbulence numeric was first order. Air at $25^{\circ} \mathrm{C}$ was used as a working fluid. Number of iteration used for the simulation was set to 500 . The solution parameters was chosen after conducting mesh independent analysis and convergence criteria analysis.

Simulation of the wind tunnel was divided into two objectives:

1. Visualize air flow profile at different air velocity

2. Modify the air flow profile to find effective separation effect

In order to achieve the simulation objectives, the variable is determined as shown as in the Table 2.

Table 2. Parameter settings

\begin{tabular}{|c|c|c|}
\hline Objectives & $\begin{array}{l}\text { Manipulate } \\
\text { variable }\end{array}$ & Constant variable \\
\hline Objective 1 & $\begin{array}{l}\text { Different velocity } \\
\text { of air flow } \\
(5.0,2.0,1.0,0.5 \\
\mathrm{m} / \mathrm{s} \text { and } 0.2 \mathrm{~m} / \mathrm{s})\end{array}$ & $\begin{array}{ll}\text { i. } & \text { Initial design of } \\
\text { wind tunnel } \\
\text { i. Angle of hopper : } \\
0^{\circ}\end{array}$ \\
\hline Objective 2 & $\begin{array}{c}\text { Different angle of } \\
\text { hopper } \\
\left(0^{\circ}, 30^{\circ}, 45^{\circ} \text {, and }\right. \\
\left.60^{\circ}\right)\end{array}$ & $\begin{array}{l}\text { i. } \begin{array}{l}\text { Initial design of } \\
\text { wind tunnel }\end{array} \\
\text { ii. } \begin{array}{c}\text { Velocity of air : } 0.2 \\
\mathrm{~m} / \mathrm{s}\end{array}\end{array}$ \\
\hline
\end{tabular}

The simulation was using governing Navier-Stokes equations. The equation was based on the conservation laws for physical properties of fluids, which included mass, energy, and momentum. The mathematical equations that were applied to the mass, momentum and energy were expressed by the following equations [11].

Continuity Equation

$\frac{\partial \rho}{\partial t}+\nabla \bullet(\rho U)=0$

Momentum Equation

$\frac{\partial \rho U}{\partial t}+\nabla \bullet(\rho U \otimes U)=-\nabla p+\nabla \bullet \tau+\mathrm{S}_{M}$

Continuity Equation

$$
\begin{aligned}
\frac{\partial\left(\rho h_{t o t}\right)}{\partial t}-\frac{\partial \rho}{\partial t}+\nabla & \bullet\left(\rho U h_{h o t}\right) \\
& =\nabla \bullet(\lambda \nabla \mathrm{T})+\nabla \bullet(U \bullet \tau)+U \bullet \mathrm{S}_{M} \\
& +\mathrm{S}_{E}
\end{aligned}
$$

Where, fluid density, $\rho$, time, $t$, vector of velocity, $\mathrm{U}$, pressure, $\mathrm{p}$, viscosity, $\mu$, temperature, $\mathrm{T}$, specific enthalpy, $\mathrm{h}$, thermal conductivity, $\lambda$, shear stress, $\tau$, mass source, $\mathrm{S}_{\mathrm{M}}$, energy source, $\mathrm{S}_{\mathrm{E}}$.

\section{Result And Discussion}

\subsection{Different air inlet velocity}

Figure 4 shows the simulation of air flow in the wind tunnel with air inlet at maximum fan speed of $5 \mathrm{~m} / \mathrm{s}$. The maximum velocity of air at the hopper is $16.5 \mathrm{~m} / \mathrm{s}$, in which can be observed at right side of the hopper from the Figure 4. Due to the high velocity built up at the hopper, the simulation shows that the POFA was being pushed back out of the hopper and blown to the surrounding, causing a major loss in obtaining ultrafine POFA.

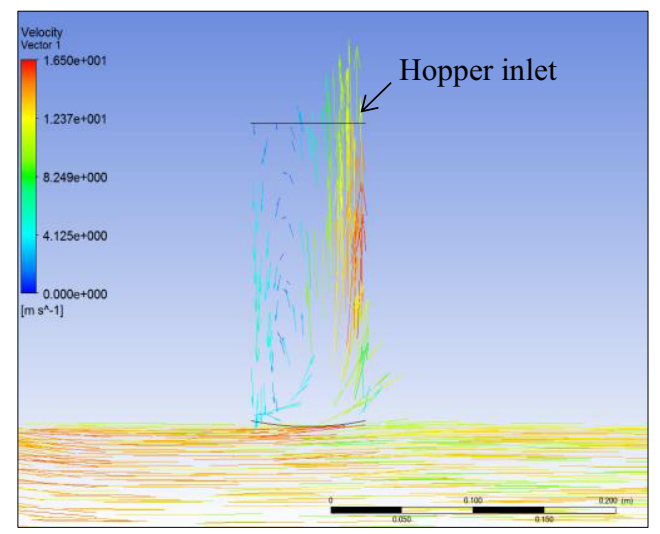

Figure 4. Air inlet velocity at $5 \mathrm{~m} / \mathrm{s}$

The air inlet velocity of $5 \mathrm{~m} / \mathrm{s}$ produced strong flow of energy at the hopper due to the sudden change at the hopper section as shown in Figure 4. Therefore, the simulation of different air inlet velocity was studied to prove that the flow energy is reduced when the air inlet velocity decreased.

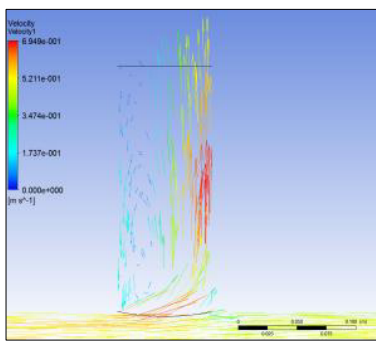

(a)

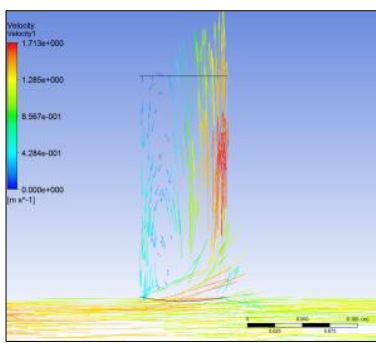

(c)

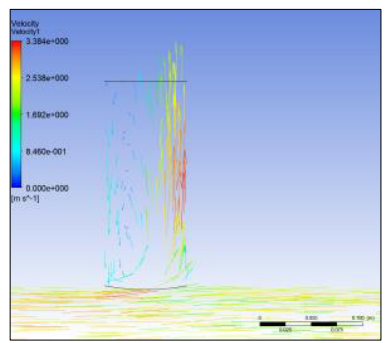

(b)

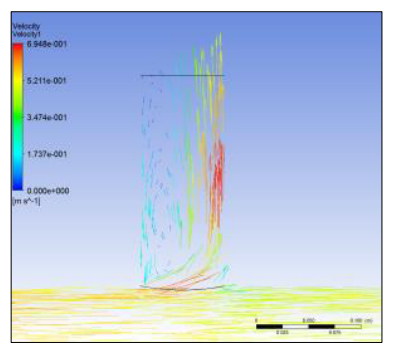

(d)
Figure 5. Air inlet at (a) $2.0 \mathrm{~m} / \mathrm{s}$, (b) $1.0 \mathrm{~m} / \mathrm{s}$, (c) $0.5 \mathrm{~m} / \mathrm{s}$ and (d) $0.2 \mathrm{~m} / \mathrm{s}$

Figure 5 showed the result for different velocity of air introduced into the tunnel. It was observed that the air flow out of the hopper was weakened when using a low velocity of air as shown in Figure 7. The flow of energy became less at the bottom of the hopper with the maximum velocity of $0.6948 \mathrm{~m} / \mathrm{s}$ occurred at the very bottom of the hopper but with less intensity

The data was plotted in the graph by constructing line $\mathrm{Y}$ from the middle of the tunnel to the top of the hopper as shown in Figure 6. The line $\mathrm{Y}$ is placed near the hopper wall. Along the line $\mathrm{Y}$, the velocity $\mathrm{V}$ is 
measured and visualized using the graph function in the software.

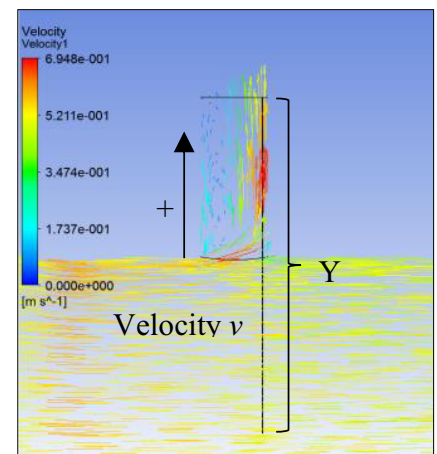

Figure 6. Position of line $\mathrm{Y}$ and velocity $\mathrm{v}$

The graph as shown in Figure 7 confirmed the air flow profile for different velocity showed the same air flow profile. As a conclusion, air flow profile at different velocity produced different intensity of energy flow. Low velocity of air would make sure less or no POFA coming of the hopper. If the air velocity was too low, the POFA could not be separated effectively.

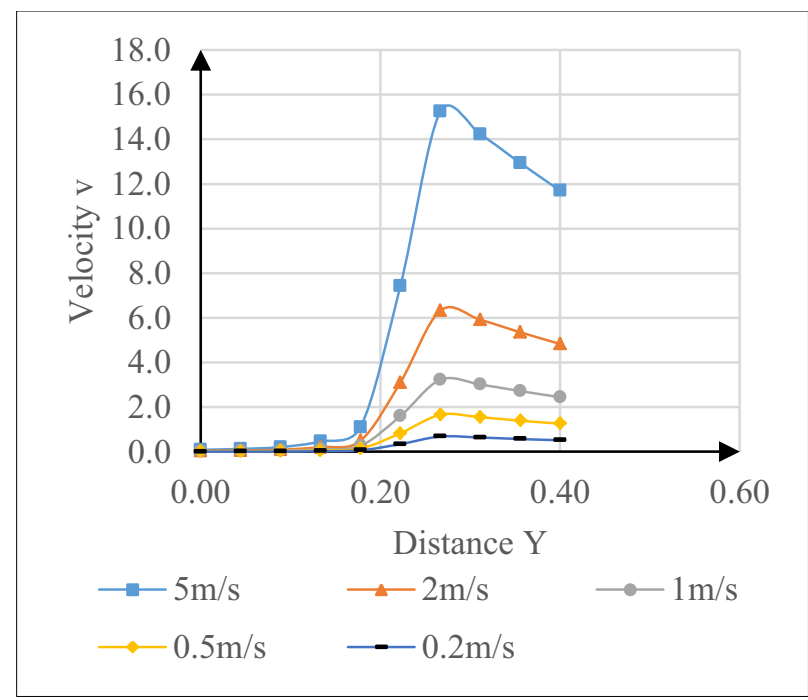

Figure 7. Velocity $\mathrm{v}$ against $\mathrm{Y}$ at different air inlet velocity

\subsection{Different angle of hopper}

The wind tunnel is simulated for a different angle of hopper to observe the air flow inside the tunnel. At certain degree of angle, it is claimed that the flow energy are varies when different angle of the hopper is installed.

Figure 8(a) shows the hopper is being slanted about $0^{\circ}$ as in the initial design with velocity of air $0.2 \mathrm{~m} / \mathrm{s}$. The intensity of air flow at the bottom of the hopper shows the air flow as high as $0.6948 \mathrm{~m} / \mathrm{s}$ is directed upwards in the hopper.

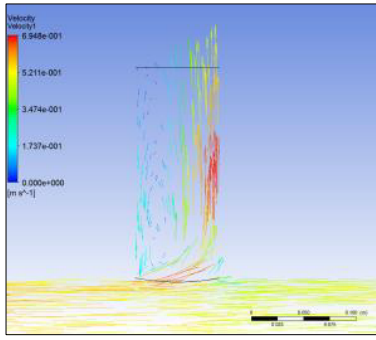

(a)

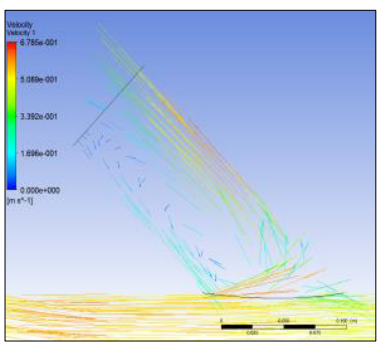

(c)

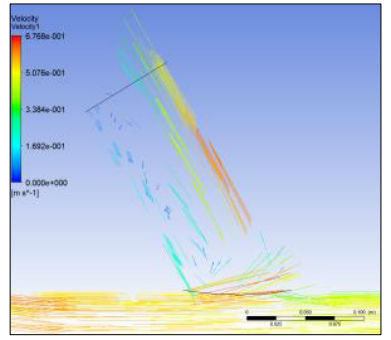

(b)

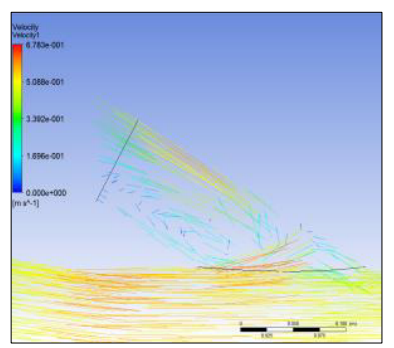

(d)
Figure 8. Hopper angles at (a) $0^{\circ}$, (b) $30^{\circ}$, (c) $45^{\circ}$ and (d) $60^{\circ}$

The hopper at different angles were simulated as shown in Figure 8. Visibly, by modifying the angle of the hopper changed the air flow profile in the hopper.

At the intersection between the hopper and the tunnel body, greater turbulence was required in order to separate the ultrafine POFA from the fine POFA. In Figure 8(a) and 8(b), the flows were mostly directed out of the hopper. The flow profiles created by the angles of $0^{\circ}$ and $30^{\circ}$ were not effective since the air flow profile is totally flowing out of the hopper.

Figure 9 showed the summary of the results of simulation at different angles of the hopper. Likely, the angle of $60^{\circ}$ exhibit the effective separation process. The negative value of the data shows the air flow was directed downward. Meanwhile, at $60^{\circ}$ angle of hopper, obvious intensity of vortices happened at the bottom of the hopper and the flow was directed downward. Consequently, mixed sizes of POFA could be separated effectively at an angle of $60^{\circ}$ of the hopper angle as well as easier to insert POFA to the hopper. If hopper angle was greater than $60^{\circ}$, there would be a tendency of the POFA to stick onto the hopper wall.

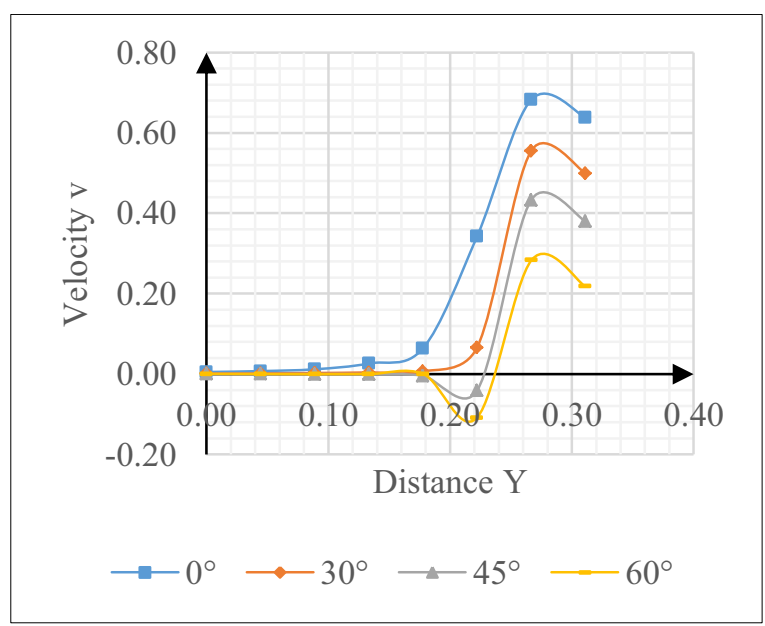

Figure 9. Velocity $\mathrm{v}$ against $\mathrm{Y}$ for different angles of the hopper 


\section{Conclusion}

As a conclusion, the design for the wind tunnel had been successfully improved. Based on the result of the simulations, the best angle of the hopper at $60^{\circ}$ was able to improve the effectiveness of the ultrafine POFA separation. The backflow of the POFA in the hopper could be minimized.

In simulation perspective, the mesh was generated successfully using ANSYS-CFX. The mesh quality was proven good as the skewness was low and the result of the simulations were converged.

The simulation results showed the presence of air backflow in the hopper, but had been reduced as the flow energy was low. Therefore a practical and economical design of a simple wind tunnel had been improved consequently would had increased the production of POFA. It was expected more research on POFA can be executed, where POFA size is concerned.

The simulations were done using a single phase flow without considering the POFA effect in the tunnel. For further research, it was recommended to use the multiphase flow in order to improve the simulation on the effect of air collision with the various sizes of POFA.

\section{References}

[1] K. Poku, "Smal-scale palm oil processing in Africa," FAO Agric. Serv. Bull. 148, pp. 1-56, 2002.

[2] Y. Basiron and M. A. Simeh, "Vision 2020 - The Palm Oil Phenomenon," Oil Palm Ind. Econ. J., vol. 5, no. 2, pp. 1-10, 2005.

[3] R. Karim, M. F. M. Zain, M. Jamil, and N. Islam, "Strength of concrete as influenced by palm oil fuel ash," Aust. J. Basic Appl. Sci., vol. 5, no. 5, pp. 990-997, 2011.

[4] L. Y. Jong and D. C. L. Teo, "Concrete containing palm oil fuel ash ( POFA ) and oil palm shell ( OPS ) subjected to elevated temperatures," UNIMAS e-Journal Civ. Eng., pp. 13-17, 2015.

[5] A. Munir, Abdullah, Huzaim, Sofyan, Irfandi, and Safwan, "Utilization of palm oil fuel ash ( POFA ) in producing lightweight foamed concrete for non-structural building material," Procedia Eng., vol. 125, pp. 739-746, 2015.

[6] N. Zainudin, "Properties of micro fine size palm oilf fuel ash (POFA) using wind tunnel production system," UNIMAS e-Journal Civ. Eng., 2015.
[7] M. Singh, N. Singh, and S. K. Yadav, "Review of design and construction of an open circuit low speed wind tunnel," Glob. J. Res. Eng., vol. 13, no. 5, pp. 1-22, 2013.

[8] Y. Q. Nguyen, "Designing, constructing, and testing a low-speed open-jet wind tunnel," Int. J. Eng. Res. Appl., vol. 4, no. 1, pp. 243-246, 2014.

[9] T. H. Yong and S. S. Dol, "Design and development of low-cost wind tunnel for educational purpose," Mater. Sci. Eng., vol. 78, pp. 318-328, 2015.

[10] S. Selvi Rajan, M. Santhoshkumar, N. Lakshmanan, N. P. S, and M. Paramasivam, "CFD analysis and wind tunnel experiment on a typical launch vehicle model," Tamkang J. Sci. Eng., vol. 12, no. 3, pp. 223-229, 2009.

[11] M. A. Ismail, A. K. Othman, H. Zen, and M. S. Misran, "CFD Modelling of pump as turbine with various number of blade for microhydro system," J. Appl. Sci. Process Eng., vol. 3, no. 1, pp. 1723, 2016. 